\title{
Subjective Sleep Quality in Iranian Patients with Spinal Cord Injury: Results of Pittsburgh Sleep Quality Index in a Referral Center
}

\author{
Keywords: Spinal cord injury; Sleep quality; Pittsburgh Sleep Quality \\ Index
}

\begin{abstract}
Background: Sleep quality is an important factor influencing quality of life in patients with spinal cord injury (SCI). Our purpose was to evaluate and report sleep quality in Iranian individuals with $\mathrm{SCI}$ in a referral center.

Methods: We assessed sleep quality by using Pittsburgh Sleep Qua lity Index (PSQI) which is the self-expressing standard questionnaire to evaluate subjective sleep quality. All patients with SCI who were referred to Brain and Spinal Injury Research Center (BASIR) and did not meet exclusion criteria entered the study.
\end{abstract}

Results: Total of 100 patients entered the study. Thirty eight patients (38\%) of SCI patients had PSQI total score higher than 5. The association between spinal cord independence score (SCIM) and sleep quality was significant in female patients in components of subjective sleep quality, necessity of using sleeping medications and daytime dysfunction (P: $0.02,0.01$ and 0.003 , respectively). Both genders had significantly less sleep disturbance and latency at higher SCIM scores. Level of injury was not associated with sleep quality. Data was collected within 4 months from J anuary 2013 till April 2013.

Conclusion: While decreased sleep quality is reported in spinal cord injured (SCI) patients, our data showed the similar frequency of reduced sleep quality in Iranian $\mathrm{SCl}$ patients in companison with general population in Tehran. Females sleep quality pattem relationship with SC IM was different from male partic ipants while they showed similarity especially in sleep la tency, duration and disturbance components. Although sleep quality in SCI population in Iran does not seem to be higher than general population, the rate is still high and requires attention.

\section{Introduction}

Decreased sleep quality is more common in spinal cord injured patients as a result of development of specific complications such as respiratory disorders and restless leg syndrome [1,2]. Moreover these sleep disturbances can increase cardiovascular diseases risk in this group of patients. Traumatic spinal cord injury (SCI) is one of the major reasons for disability worldwide. The incidence rate varies among different countries due to variations in transport system and other environmental factors. Iran is one of the countries that stand in highest rates of road accidents [3] and annual incidence of spinal cord injury is noticeable in this country. Along with its increased prevalence recently [4], it occurs mostly in younger section of population especially between second and fourth decades [5]. By considering the tremendous effect that sleep disturbances exert on

\section{Journal of Neurology and Psychology}

Marzieh Matin ${ }^{1}$, Seyedeh Mohadeseh Taher Otaghsara ${ }^{1}$, Sahar Latifi ${ }^{1 *}$, Abbas Norouzi Javidan ${ }^{1}$, Davood Koushki ${ }^{2}$, Farima Abedi ${ }^{1}$ and Baharak Hariri Marand ${ }^{3}$

${ }^{1}$ Brain and Spinal Injury Research Center (BASIR), Tehran University of Medical Sciences, Imam Khomeini Medical Center, Tehran, Iran

${ }^{2}$ Iran University of Medical Sciences, Tehran, Iran ${ }^{3}$ Azad University of Medical Sciences, Tehran, Iran

*Address for Correspondence

Sahar Latifi, MD, Brain and Spinal Injury Research Center (BASIR), Tehran University of Medical Sciences, Imam Khomeini Medical Center, Keshavarz Boulevard, Tehran, Iran, Tel: 00982144908768; E-mail: s-latifi@farabi.tums.ac.ir

Copyright: (c) 2014 Matin M, et al. This is an open access article distributed under the Creative Commons Attribution License, which permits unrestricted use, distribution, and reproduction in any medium, provided the original work is properly cited.

Submission: 16 December 2013

Accepted: 05 February 2014

Published: 10 February 2014

Reviewed \& Approved by: Dr. Pradeep Sahota

Department of Neurology, University of Missouri School of Medicine, USA

quality of life along with developing life-threatening side effects such as sudden death [6], cardiovascular diseases [7,8] and restless leg syndrome [9], assessing the prevalence of reduced sleep quality may help to lighten an overall view of present conditions. Spinal cord injured population is one of the sensitive and fragile group of patients that are liable to develop sleep disturbances. Our purpose was to evaluate sleeping conditions in a referral center in Iran by Pittsburgh Sleep Quality Index. By considering the numerous factors that effect on sleep quality including environmental factors, living conditions along with physical and emotional supports provided by family and government, sleep health may differ from one region to another. We tried to determine sleep condition in Iranian patients who were referred to Brain and Spinal Injury Research Center (BASIR) from all parts of the country.

\section{Methods}

\section{Study design}

This study was designed as a cross sectional investigation based on obtaining information by standard questionnaires. These surveys were performed on patients' routine visits. Patients were invited to participate in survey voluntarily. The study was approved by the research ethics committee of Tehran University of medical sciences. Data was collected within 4 months from January 2013 till April 2013.

\section{Participants}

All patients with spinal cord injury who were referred to Brain and Spinal Injury Research Center (BASIR) were invited to participate in this survey. By considering the depressive phase which occurs mostly in acute phase of SCI and may continue up to first one year [10], we excluded patients with post injury duration of less than 1 year to omit the bias effect of depression on sleep condition. Individuals who had sleep disturbances before injury occurrence were excluded as well. 
Citation: Matin M, Taheri Otaghsara SM, Latifi S, Javidan AN, Koushki D, et al. Subjective Sleep Quality in Iranian Patients with Spinal Cord Injury: Results of Pittsburgh Sleep Quality Index in a Referral Center. J Neurol Psychol. 2014;2(1): 4.

ISSN: 2332-3469

\section{Sleep quality assessment questionnaire}

Data were obtained using standard questionnaire of Pittsburgh to assess sleep quality. The Pittsburgh Sleep Quality Index (PSQI) is the recommended assessment tool to evaluate subjective sleep quality over the past month [11] and it is based on patients' self-report of their sleep habits. This questionnaire evaluates sleep quality in 7 components and the sum of scores presents a global score of sleep quality. These components include subjective sleep quality, sleep latency, sleep duration, habitual sleep efficiency, sleep disturbances, use of sleeping medication and daytime dysfunction. The score for each item ranges from 0 to 3. Reliability of the original English questionnaire was evaluated previously by Backhaus et al. [12] using a test-retest reliability. Poor sleep quality was defined by scores higher than 5 with a diagnostic sensitivity of $89.6 \%$ and a specificity of $86.5 \%$ [11]. The Persian version of this questionnaire was previously used in several investigations and had acceptable reliability [13-15]. Consequently, the reliability and validity of Persian instrument was documented as the standard questionnaire to assess sleep quality [16]. We used this instrument to obtain a score representing subjective sleep quality in patients with spinal cord injury.

\section{Spinal Cord Independence Measure (SCIM)}

We used spinal cord independence measure III to evaluate patients' independency and ability in conventional daily activities. This measure has been especially designed for individuals with SCI to assess the ability in performing routine tasks [17]. Among three published version of SCIM, third edition has been shown to have adequate reliability and validity in spinal cord injured patients $[18,19]$. This instrument consists of three subscales: self-care $(0-20)$, mobility ( $0-40$ scores) and respiration and sphincter management ( 0 40 scores) which comes to a maximum score of 100 . Higher scores illustrate more independency (Table 1).

\section{Clinical measures}

Patients' demographic characteristics including age and gender were indexed. Level of injury was determined by physical examination along with imaging aids and was confirmed by a neurology specialist.

\section{Analysis}

We used SPSS software version 18 (SPSS, Inc., Chicago IL, USA) to report frequencies and mean scores \pm standard deviations of each component in patients with SCI. Independence $t$ test and one-way analysis of variances (ANOVA) was used to compare continuous values. $\mathrm{P}$-value $<0.05$ was considered as statistically significant.

\section{Results}

Total of 100 patients with SCI completed the PSQI questionnaire in this study. No complaint of previous sleep disturbances before SCI occurrence was detected. Gender distribution consisted of mostly male individuals (74 (74\%) males and 26 (26\%) females). Mean age was $31.97 \pm 12.07$ years old in male patients and $32.73 \pm 10.14$ years old in female individuals. The most common injury level was T12 in both male and female patients. In male population $21(28.4 \%)$ had injury at cervical level, 48 (64.9\%) at thoracic and $5(6.8 \%)$ at lumbar level. In female patients 8 women (30.8\%) had injury at cervical, $17(65.4 \%)$ at thoracic and $1(6.8 \%)$ at lumbar level. There was no
Table 1: Spinal Cord Independence Measure III components and items; higher scores represent more independency and ability in performing routine daily tasks.

\begin{tabular}{|c|c|c|}
\hline Component & Item & Score \\
\hline \multirow[t]{4}{*}{ Self-care } & Feeding & 3 \\
\hline & Bathing & 6 \\
\hline & Dressing & 8 \\
\hline & Grooming & 3 \\
\hline \multirow[t]{9}{*}{ Mobility } & Bed mobility & 6 \\
\hline & bed-wheelchair transfer & 2 \\
\hline & wheelchair-toilet-tub transfer & 2 \\
\hline & Indoors mobility & 8 \\
\hline & $\begin{array}{l}\text { Outdoor mobility in } 10-100 \text { meter } \\
\text { distance }\end{array}$ & 8 \\
\hline & $\begin{array}{l}\text { Outdoor mobility in more than } 100 \text { meter } \\
\text { mobility }\end{array}$ & 8 \\
\hline & Stair management & 3 \\
\hline & Wheelchair-car transfer & 2 \\
\hline & Wheelchair-ground transfer & 1 \\
\hline \multirow[t]{4}{*}{$\begin{array}{l}\text { Respiration and sphincter } \\
\text { management }\end{array}$} & Bladder management & 15 \\
\hline & Bowel management & 10 \\
\hline & Toilet usage & 5 \\
\hline & Respiration & 10 \\
\hline Total & & 100 \\
\hline
\end{tabular}

significant association between injury level and sleep latency ( $\mathrm{P}$ : 0.09), sleep duration (p: 0.32), habitual sleep efficiency (p: 0.66), sleep disturbance (p: 0.54), need for sleep medication (p: 0.80) and daytime dysfunction (0.45). Age was not also associated with any of the sleep quality components (Table 2).

In Pittsburgh questionnaire, score 0 represents 'never', score 1 represents 'once a week' and scores 2 and 3 illustrate 'twice a week' and 'more than 3 times in a week', respectively. All this scores evaluate the frequency of these classified disorders in the past month. Table 3 represents the frequencies of each component of Pittsburgh sleep quality index in spinal cord injured males and females.

Mean total score was $4.27 \pm 4.25$ in male patients and $4.73 \pm 3.96$ in female participants. According to previous published literatures, total score $>5$ is highly associated with poor sleep quality $[11,12]$. In this study $64.9 \%$ of male participants (n: 48 ) had total score lower than 5. Meanwhile in female individuals with SCI, poor sleep quality was detected in $46.2 \%$ (n: 12) of patients. However this difference was not statistically significant (P: 0.22 ).

Mean SCIM score was $52.0 \pm 21.87$ (Range: 6-84) in male group and $44.90 \pm 22.30$ (range: 11-88) in female group. In both female and male groups patients with higher SCIM group obtained the most frequent score 0 in sleep latency which shows that better SCIM score as a marker of patients' ability and independence is significantly related to better sleep initiation (Table 2). Moreover the same results were found on the relationship between sleep disturbance parameter and SCIM score in both genders. Sleep disturbance was defined as becoming awake due to occurrence of any discomforts including 
Citation: Matin M, Taheri Otaghsara SM, Latifi S, Javidan AN, Koushki D, et al. Subjective Sleep Quality in Iranian Patients with Spinal Cord Injury: Results of Pittsburgh Sleep Quality Index in a Referral Center. J Neurol Psychol. 2014;2(1): 4.

dyspnea, cough, feeling sever heat or coldness, nightmare and pain. Patients with higher SCIM score experienced these sleep disturbing factors less than those with lower scores (P-value: 0.028 and 0.048 in male and female groups, respectively). On the other hand only female participants revealed less need to sleep medication in higher SCIM scores (P-value: $0.019, \mathrm{r}=0.50$ ) while no such relationship was found in male patients. Similarly only female patients showed less daytime dysfunction by higher SCIM score (P-value: 0.003, r= 0.62) (Table 2).

\section{Discussion}

Reduced sleep quality is an important factor affecting quality of life and daily function. The estimated prevalence of poor sleep quality has been increased in general population [20]. Spinal cord injured individuals have additive etiologies that raise poor sleep quality's prevalence in these patients. It is estimated that $37 \%$ of general population in Tehran suffer from reduced sleep quality assessed by PSQI [21] and here we report that $38 \%$ of patients with spinal cord injury who had no previous history of sleep problems before injury, have poor sleep quality (Pittsburgh total score higher than 5). Although higher rate of poor sleep quality in spinal cord injured patients in comparison with general population was expected, our data show that the incidence of reduced sleep quality in Iranian patients with SCI is similar to general population when using the same assessment instrument. It seems that physiologic factors that influence sleep quality are complex as Verheggen et al. [22] reported absence of evening melatonin increase in tetraplegic patients while the increased rate of poor sleep quality was similar in paraplegics and tetraplegics. Besides complex role of physiologic and psychological factors, other involved causes that interfere with sleeping in SCI individuals such as pain $[1,24,25]$, sleep interruption due to bladder distension and incontinence [5] should be considered. It is noticeable that even by defining many etiologies that cause sleep disturbance in SCI population, the incidence of poor sleep quality in Iranian patients are similar to general population of Tehran which was reported previously by Asghari et al. [21]. However this rate of poor sleepquality is still high and needs attention.

The rate of reduced sleep quality was higher in female patients (46.2\% in females versus $35.1 \%$ in males) though this difference was not statistically significant (P: 0.22$)$. Moreover the sleep quality pattern relationship with SCIM score was different among males and females. While both genders experienced more sleep disturbance and latency with lower SCIM scores, only female patients revealed less need to sleep medications (P: 0.019) and daytime dysfunction (P: 0.03 ) at higher scores of SCIM. The differences in sleeping pattern between male and female was previously reported and the prominent trend is toward higher prevalence of sleep disturbances in women [20,25-27]. Ghalichi et al. [13] explained the higher rate of sleep problems in females with higher prevalence of undesirable selfrated health in women. These results become more interesting while considering higher prevalence of obstructive sleep apnea (OSA) in males [28] which shows that other factors interfering with sleep is more prominent and severe in spinal cord injured females because women experience more sleep problems even with lower rate of OSA.

The association between spinal injury level and sleep disturbance was controversial in previous literatures. While Biering-Sørensen et al. [1] detected no relationship between injury level and its completeness with sleep quality, Sheer et al. [29] found that only cervical SCI was correlated with reduction of sleep efficiency. Our data showed no significant association between injury level and sleep quality which is in line with Verheggen et al. [22] assessing sleep quality in SCI patients with PSQI. Although some sleep disturbing factors such as autonomic dysreflexia is known to be more frequent in higher spinal cord lesions [30-32], totally it seems that sleep initiation and duration and patients satisfaction of sleep quality does not differ in SCI patients with different injury levels.

Table 2: The effect of age and spinal cord independence measure (SCIM) on sleep quality based on Pittsburgh indexes.

\begin{tabular}{|l|c|c|c|}
\hline \multicolumn{1}{|c|}{ Components } & \multicolumn{2}{c|}{ Male (P-value) } & \multicolumn{2}{c|}{ Female (P-value) } \\
\cline { 2 - 4 } & SCIM score & Age & $0.024(\mathrm{r}=-0.38)$ \\
\hline Subjective sleep quality & 0.44 & 0.65 & $0.014(\mathrm{r}=-0.53)$ \\
\hline Sleep latency & $0.04(\mathrm{r}=-0.23)$ & 0.30 & 0.45 \\
\hline Sleep duration & 0.37 & 0.92 & 0.21 \\
\hline Habitual sleep efficiency & 0.51 & 0.21 & 0.93 \\
\hline Sleep disturbance & $0.028(\mathrm{r}=-0.21)$ & 0.63 & $0.048(\mathrm{r}=-0.43)$ \\
\hline Requirement of sleep medications & 0.41 & 0.18 & $0.019(\mathrm{r}=-0.50)$ \\
\hline Daytime dysfunction & 0.26 & 0.85 & 0.31 \\
\hline
\end{tabular}

SCIM: Spinal Cord Independence Measure

Table 3: Frequencies of sleep quality components scores based on Pittsburgh sleep quality index in spinal cord injured patients.

\begin{tabular}{|c|c|c|c|c|c|c|c|c|}
\hline \multirow[t]{2}{*}{$\mathbf{x c}$} & \multicolumn{4}{|c|}{$\begin{array}{l}\text { Male patients, Number (\%) } \\
(\mathrm{n}: 74)\end{array}$} & \multicolumn{4}{|c|}{$\begin{array}{l}\text { Female patients, Number (\%) } \\
\qquad(\mathrm{n}: 26)\end{array}$} \\
\hline & Score 0 & Score 1 & Score 2 & Score 3 & Score 0 & Score 1 & Score 2 & Score 3 \\
\hline Subjective sleep quality & $24(32.4 \%)$ & $33(44.6 \%)$ & $11(14.9 \%)$ & $6(8.1 \%)$ & $7(26.9 \%)$ & $12(46.2 \%)$ & $5(19.2 \%)$ & $2(7.7 \%)$ \\
\hline Sleep latency & $42(56.8 \%)$ & $9(12.2 \%)$ & $9(12.2 \%)$ & $14(18.9 \%)$ & $12(46.2 \%)$ & $3(11.5 \%)$ & $8(30.8 \%)$ & $3(11.5 \%)$ \\
\hline Sleep duration & $42(56.8 \%)$ & $16(21.6 \%)$ & $10(13.5 \%)$ & $6(8.1 \%)$ & $12(46.2 \%)$ & $7(26.9 \%)$ & $6(23.1 \%)$ & $1(3.8 \%)$ \\
\hline Habitual sleep efficiency & $65(87.8 \%)$ & $8(10.8 \%)$ & $1(1.4 \%)$ & $0(0 \%)$ & $25(96.2 \%)$ & $1(3.8 \%)$ & $0(0 \%)$ & $0(0 \%)$ \\
\hline Sleep disturbance & $47(63.5 \%)$ & $22(29.7 \%)$ & $4(5.4 \%)$ & $1(1.4 \%)$ & $14(53.8 \%)$ & $11(42.3 \%)$ & $1(3.8 \%)$ & $0(0 \%)$ \\
\hline $\begin{array}{l}\text { Requirement of sleep } \\
\text { medications }\end{array}$ & $57(77 \%)$ & $6(8.1 \%)$ & $4(5.4 \%)$ & $7(9.5 \%)$ & $18(69.2 \%)$ & $3(11.5 \%)$ & $5(19.2 \%)$ & $0(0 \%)$ \\
\hline Daytime dysfunction & $44(59.5 \%)$ & $20(27 \%)$ & $8(10.5 \%)$ & $2(2.7 \%)$ & $14(53.8 \%)$ & $7(26.9 \%)$ & $4(15.4 \%)$ & $1(0.8 \%)$ \\
\hline
\end{tabular}


Citation: Matin M, Taheri Otaghsara SM, Latifi S, Javidan AN, Koushki D, et al. Subjective Sleep Quality in Iranian Patients with Spinal Cord Injury: Results of Pittsburgh Sleep Quality Index in a Referral Center. J Neurol Psychol. 2014;2(1): 4.

ISSN: 2332-3469

\section{Conclusion}

While decreased sleep quality is reported in spinal cord injured (SCI) patients, our data showed the similar frequency of poor sleep quality in Iranian SCI patients with general population in Tehran. Totally $38 \%$ of patients with SCI suffered from poor sleep quality assessed by Pittsburgh Sleep Quality Index. Although reduced sleep quality in SCI population in Iran does not seem to be higher than general population, the rate is still high and requires attention. Sleep latency and disturbance was less frequent in higher SCIM scores in both genders while only female patients showed less need for sleep medications and less daytime dysfunction at higher SCIM score.

\section{References}

1. Biering-Sørensen F, Biering-Sørensen M (2001) Sleep disturbances in the spinal cord injured: an epidemiological questionnaire investigation, including a normal population. Spinal Cord 39: 505-513.

2. Jensen MP, Hirsh AT, Molton IR, Bamer AM (2009) Sleep problems in individuals with spinal cord injury: frequency and age effects. Rehabil Psychol 54: 323-331.

3. Bahadorimonfared A, Soori H, Mehrabi $Y$, Delpisheh A, Esmaili A, et al. (2013) Trends of fatal road traffic injuries in iran (2004-2011). PLoS One 8 e65198.

4. Devivo MJ (2012) Epidemiology of traumatic spinal cord injury: trends and future implications. Spinal Cord 50: 365-372.

5. Giannoccaro MP, Moghadam KK, Pizza F, Boriani S, Maraldi NM, et al (2013) Sleep disorders in patients with spinal cord injury. Sleep Med Rev 17 399-409.

6. Punjabi NM, Caffo BS, Goodwin JL, Gottlieb DJ, Newman AB, et al. (2009) Sleep-disordered breathing and mortality: a prospective cohort study. PLoS Med 6: e1000132.

7. Rakel RE (2009) Clinical and societal consequences of obstructive sleep apnea and excessive daytime sleepiness. Postgrad Med 121: 86-95.

8. Bradley TD, Floras JS (2009) Obstructive sleep apnea and its cardiovascular consequences. Lancet 373: 82-93.

9. Telles SC, Alves RC, Chadi G (2011) Periodic limb movements during sleep and restless legs syndrome in patients with ASIA A spinal cord injury. J Neurol Sci 303: 119-123

10. Ullrich PM, Lincoln RK, Tackett MJ, Miskevics S, Smith BM, et al. (2013) Pain, depression, and health care utilization over time after spinal cord injury. Rehabil Psychol 58: 158-165.

11. Buysse DJ, Reynolds CF 3rd, Monk TH, Berman SR, Kupfer DJ (1989) The Pittsburgh Sleep Quality Index: a new instrument for psychiatric practice and research. Psychiatry Res 28: 193-213.

12. Backhaus J, Junghanns K, Broocks A, Riemann D, Hohagen F (2002) Testretest reliability and validity of the Pittsburgh Sleep Quality Index in primary insomnia. J Psychosom Res 53: 737-740.

13. Ghalichi L, Pournik O, Ghaffari M, Vingard E (2013) Sleep quality among health care workers. Arch Iran Med 16:100-103.

14. Reza H, Kian N, Pouresmail Z, Masood K, Sadat Seyed Bagher M, et al. (2010) The effect of acupressure on quality of sleep in Iranian elderly nursing home residents. Complement Ther Clin Pract 16: 81-85.
15. Malakouti SK, Foroughan M, Nojomi M, Ghalebandi MF, Zandi T (2009) Sleep patterns, sleep disturbances and sleepiness in retired Iranian elders. Int J Geriatr Psychiatry 24: 1201-1208.

16. Farrahi Moghaddam J, Nakhaee N, Sheibani V, Garrusi B, Amirkafi A (2012) Reliability and validity of the Persian version of the Pittsburgh Sleep Quality Index (PSQI-P). Sleep Breath 16: 79-82.

17. Catz A, Itzkovich M, Steinberg F, Philo O, Ring H, et al. (2001) The CatzItzkovich SCIM: a revised version of the Spinal Cord Independence Measure. Disabil Rehabil 23: 263-268.

18. Anderson K, Aito S, Atkins M, Biering-Sørensen F, Charlifue S, et al. (2008) Functional recovery measures for spinal cord injury: an evidence-based review for clinical practice and research. J Spinal Cord Med 31: 133-144.

19. Catz A, Itzkovich M, Tesio L, Biering-Sorensen F, Weeks C, et al. (2007) A multicenter international study on the Spinal Cord Independence Measure, version III: Rasch psychometric validation. Spinal Cord 45: 275-291.

20. Ohayon MM (2002) Epidemiology of insomnia: what we know and what we still need to learn. Sleep Med Rev 6: 97-111.

21. Asghari A, Farhadi M, Kamrava SK, Ghalehbaghi B, Nojomi M (2012) Subjective sleep quality in urban population. Arch Iran Med 15: 95-98.

22. Verheggen RJ, Jones H, Nyakayiru J, Thompson A, Groothuis JT, et al. (2012) Complete absence of evening melatonin increase in tetraplegics. FASEB J 26: 3059-3064.

23. Norrbrink Budh C, Hultling C, Lundeberg T (2005) Quality of sleep in individuals with spinal cord injury: a comparison between patients with and without pain. Spinal Cord 43: 85-95.

24. Widerstrom-Noga EG, Felipe-Cuervo E, Yezierski RP (2001) Chronic pain after spinal injury: interference with sleep and daily activities. Arch Phys Med Rahabil 82: 1571-1577.

25. Nojomi M, Ghalhe Bandi MF, Kaffashi S (2009) Sleep pattern in medical students and residents. Arch Iran Med 12: 542-549.

26. Li RH, Wing YK, Ho SC, Fong SY (2002) Gender differences in insomnia--a study in the Hong Kong Chinese population. J Psychosom Res 53: 601-609.

27. Vitiello MV, Larsen LH, Moe KE (2004) Age-related sleep change: Gender and estrogen effects on the subjective-objective sleep quality relationships of healthy, noncomplaining older men and women. J Psychosom Res 56: 503510.

28. Stockhammer E, Tobon A, Michel F, Eser P, Scheuler W, et al. (2002) Characteristics of sleep apnea syndrome in tetraplegic patients. Spinal Cord 40: 286-294.

29. Scheer FA, Zeitzer JM, Ayas NT, Brown R, Czeisler CA, et al. (2006) Reduced sleep efficiency in cervical spinal cord injury; association with abolished night time melatonin secretion. Spinal Cord 44: 78-81.

30. Teasell RW, Arnold JM, Krassioukov A, Delaney GA (2000) Cardiovascular consequences of loss of supraspinal control of the sympathetic nervous system after spinal cord injury. Arch Phys Med Rehabil 81: 506-516.

31. Mathias CJ, Bannister R (2002) Autonomic disturbances in spinal cord esions. In: Mathias CJ, ed. Autonomic failure: A textbook of clinical disorders of the autonomic nervous system. Oxford Univ Pr, Oxford 839-881.

32. Breault G, Altaweel W, Corcos J (2008) Management of autonomic dysreflexia. Curr Blad Dysfun Report 3: 13-16 